\title{
BIOMECHANICAL ASSESSMENT OF THE STRENGTH OF VOLLEYBALL PLAYERS IN DIFFERENT STAGES OF THE TRAINING MACROCYCLE
}

\author{
MARCIN ŚLIWA ${ }^{1}$, TOMASZ SACEWICZ ${ }^{2}$ \\ Józef Piłsudski University of Physical Education in Warsaw, Faculty of \\ Physical Education and Sport in Biała Podlaska, Department of Football and \\ Volleyball ${ }^{1}$, Department of Biomechanics and Computer Science ${ }^{2}$
}

\author{
Mailing address: Marcin Śliwa, Faculty of Physical Education and Sport, Department of Football \\ and Volleyball, 2 Akademicka Street, 21-500 Biała Podlaska, tel.: +48 83 3428879, \\ fax: +48 83 3428800, e-mail: marcin.sliwa@awf-bp.edu.pl
}

\begin{abstract}
Introduction. In order to help volleyball players achieve superior results, their coaches are constantly seeking new training methods. One of the methods used to improve the effectiveness of the training that is being implemented is conducting tests which make it possible to assess the player's locomotor system in terms of its motor and biomechanical functions. The aim of the study was to determine the torque of the knee flexor and extensor muscles of volleyball players in three stages of the annual macrocycle. Material and methods. The study involved 14 volleyball players. Torque was assessed using the BIODEX System 4 Pro at the angular velocities of $60 \%$ and $180 \%$, in three periods of the annual training macrocycle. Results. After the preparatory training period, there was a statistically significant increase in the torque of the flexor and extensor muscles of the lower limbs, both for the lower velocity ( $\mathrm{p} \leq 0.02$ for the right limb and $\mathrm{p} \leq 0.024$ for the left limb) and the higher one ( $\mathrm{p} \leq 0.03$ for the right limb and $\mathrm{p} \leq 0.034$ for the left limb). After the preliminary round, statistically insignificant changes were found for the torque values obtained at both velocities. Conclusions. The study showed that frequent monitoring of players can help assess their strength capacity in a more reliable way. The results of such measurements carried out in different periods of the volleyball season can help evaluate the players' strength at a given moment, verify and modify the training methods which are being used, and approach each player individually.
\end{abstract}

Key words: volleyball, knee joint, muscle torque, annual macrocyle

\section{Introduction}

Preparing volleyball players for the game is a responsible task. Coaches need to implement the training in a well thought out and organised way, with due diligence, and without risking the health of the players. In order for the players to accomplish the training goals and tasks, it is necessary to maximise the effectiveness and efficiency of the training. There are two basic sources of knowledge concerning this issue. The first one is scientific research that indicates which training methods and techniques are the most effective. The second source is the coaches and players, who have the opportunity to test the results of research studies, on the one hand, and who develop training programmes, on the other [1]. Verifying the results of research makes it possible both to foster the development of superior skills in a given sports discipline and to minimise the risk of injury [2, 3].

One of the key research methods used is the measurement of strength or speed-strength, which helps assess the locomotor system in terms of its motor and biomechanical functions. Analysing the muscle strength of a given player by comparing it to normative data makes it possible to assess their skills in relation to those of other players with similar somatic features $[2,4,5]$ and identify any strength deficit between the two limbs [6].

The players' speed-strength and strength capacities can be assessed based on measuring the torque of the muscles of their upper or lower limbs. Such measurements are conducted under isometric $[2,5,7,8]$ or isokinetic conditions $[6,9,10$, 11]. The strength capacity of a player can also be evaluated using appropriate biomechanical models $[12,13]$. The results of measurements or computer simulations provide substantial quantitative and qualitative data concerning the player's fitness level and the effectiveness of the training methods applied.

An analysis of the literature on the subject reveals that there are many publications which present isokinetic studies involving volleyball players conducted both in Poland and in other countries. The isokinetic method is one of the methods which are used the most frequently to assess the strength capacity of the groups of muscles which act on the knee joint and evaluate the function of the knee joint after injuries have been sustained $[14,15,16,17]$. Such studies have involved, among others, the members of the national teams of Brazil [8], Spain [18], and Australia [10, 19], as well as league players [5, 20, 21, 22, 23].

Regular isokinetic tests conducted over a longer period of time also make it possible to monitor various types of changes caused by the annual training programme [18, 24]. In the research mentioned above $[18,24]$ the tests were carried out twice and three times, but only one was performed during the annual competitive macrocycle. Thus, they did not illustrate the changes in the torque of the flexors and extensors of the knee joint in the macrocycle. 
Taking the above into consideration, the aim of the current study was to determine the changes in the torque of the knee flexors and extensors in the annual macrocycle in a group of volleyball players.

\section{Material and methods}

The study was conducted among 14 volleyball players from a second-league team. Basic anthropometric data (the mean and standard deviation, SD) are shown in table 1. All of the subjects declared that their dominant lower limb was the right one. Before the measurements were performed, the subjects were informed about the aim of the study and consented to participating in it. The study was approved by the Senate Ethics Committee of the University of Physical Education in Warsaw.

Table 1. Anthropometric data of the volleyball players $(\mathrm{N}=14)$

\begin{tabular}{|c|c|c|c|c|}
\hline & Age [years] & Height [cm] & $\begin{array}{c}\text { Body mass } \\
{[\mathbf{k g}]}\end{array}$ & $\begin{array}{c}\text { BMI } \\
{\left[\mathbf{k g} / \mathbf{m}^{2}\right]}\end{array}$ \\
\hline Mean & 21.6 & 190.3 & 86.1 & 23.67 \\
\hline SD & 2.6 & 3.64 & 7.84 & 1.7 \\
\hline
\end{tabular}

The torque of the knee flexors and extensors was measured using Biodex System Pro 4. The measurements were conducted at the end of three different periods of the annual macrocycle: the transition period (first measurement), the preparatory period (second measurement), and the competitive period (third measurement). During the transition period, the subjects performed recreational exercise (they played football, beach volleyball, and basketball, as well as doing running). In the remaining two periods, the team trained five times a week, and two training sessions were devoted to strength training. Strength training in the preparatory period involved high-intensity exercise, while that in the competitive period focused on high-volume exercise.

Before each measurement was conducted, the subjects were immobilised so that the movement in the knee joint could be isolated. They were instructed and verbally encouraged to flex and extend the muscles acting on the knee joint with as much force as possible. The test consisted of two series of movement. In the first one, the subjects performed 5 cycles of flexing and extending the knee joint muscles at an angular velocity of $60 \%$, and in the second one, they performed 10 cycles of flexing and extending their muscles at an angular velocity of $180 \%$ s. The measurement was performed for both lower limbs. Each measurement was preceded with a 10-minute warm-up consisting in running continuously at a pace of the subjects' choice.

The values obtained in the measurement of muscle torque were analysed statistically in order to establish whether the differences between different phases of the macrocycle were statistically significant. First, the data was tested for normality of distribution and homogeneity of variances using the Shapiro-Wilk test and Bartlett's test. As the data was found to be normally distributed and to have equal variances, a one-way ANOVA test with repeated measures was performed. In the final stage of statistical testing, the Bonferroni test was used to interpret the significant differences between the mean values of the variables.

\section{Results}

The strength capacity of the volleyball players was assessed based on the maximum values obtained for the torque of the knee flexors and extensors in isokinetic measurement at the angular velocities of $60 \%$ s and $180 \%$ s (fig. 1).
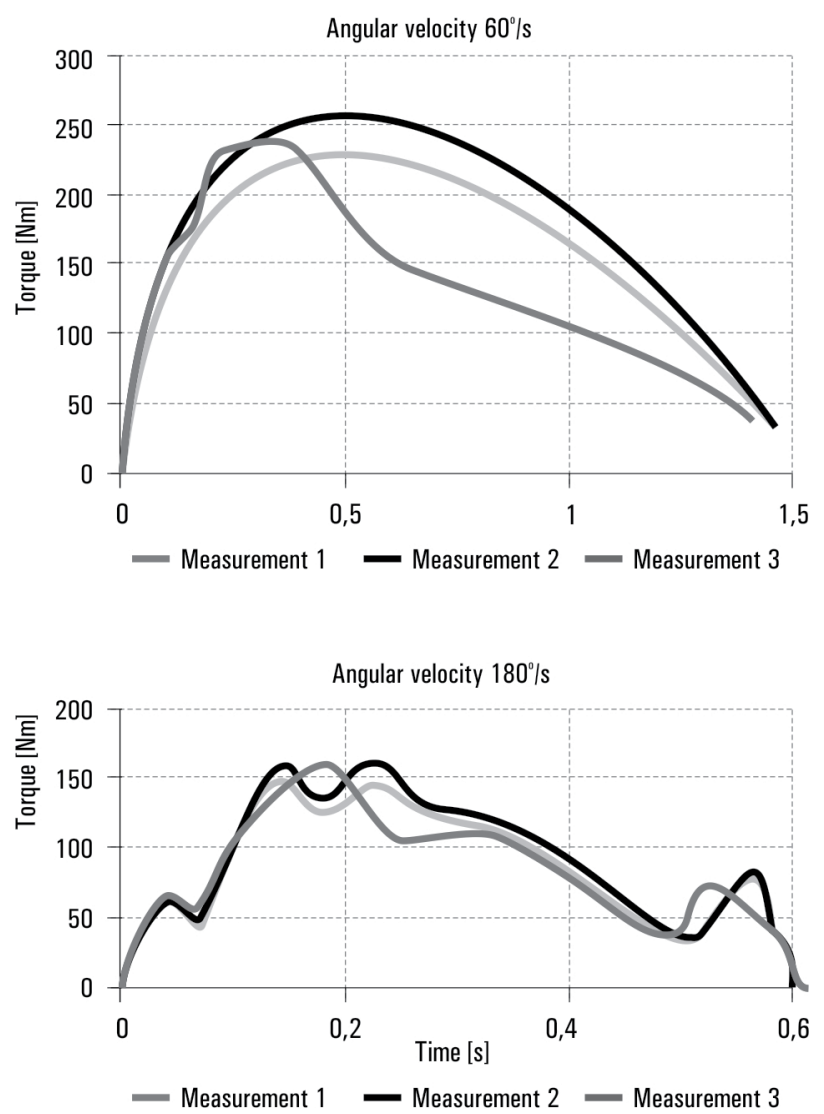

Figure 1. Sample torque-time curve of the knee extensors of a libero player at the velocities of $60 \% \mathrm{~s}$ and $180 \% \mathrm{~s}$

The changes in peak torque values of the knee flexors and extensors in the three phases of the annual macrocycle are presented in figures 2 and 3 . As far as the measurements conducted at the velocity of $60 \%$ are concerned, it was found that after the preparatory period, there was a mean increase of $9.6 \%$ in the torque of both the flexors and extensors of both lower limbs (fig. 2). The third measurement, which took place after the preliminary round of the season, revealed a slight decrease in mean peak torque values (of $2.4 \%$ ), although those obtained for the extensors of the left limb had risen by 1.3\%. The only differences which were statistically significant were those between the values of the torque of the extensors between the first and second measurements ( $\mathrm{p} \leq 0.02$ for the right limb and $\mathrm{p} \leq 0.024$ for the left one).

As for the data obtained in the measurement performed at the velocity of $180 \%$, it was found that the peak torque of the flexors and extensors of both limbs had increased by $10 \%$ between the first and second measurements (fig. 3). Moreover, the analysis revealed that there had been a mean increase in torque values obtained for the flexors and extensors between the second and third measurements (of $2.7 \%$ ); however, the torque of the flexors had decreased by $1.6 \%$ and that of the extensors of the left limb had increased by $8.3 \%$. Similarly as was the case with the velocity of $60 \%$, the only differences found for the velocity of $180^{\circ}$ s which were statistically significant were those between the torque values obtained for the extensors of both limbs between the first and second measurements ( $p \leq 0.03$ for 
the right limb and $\mathrm{p} \leq 0.034$ for the left one).

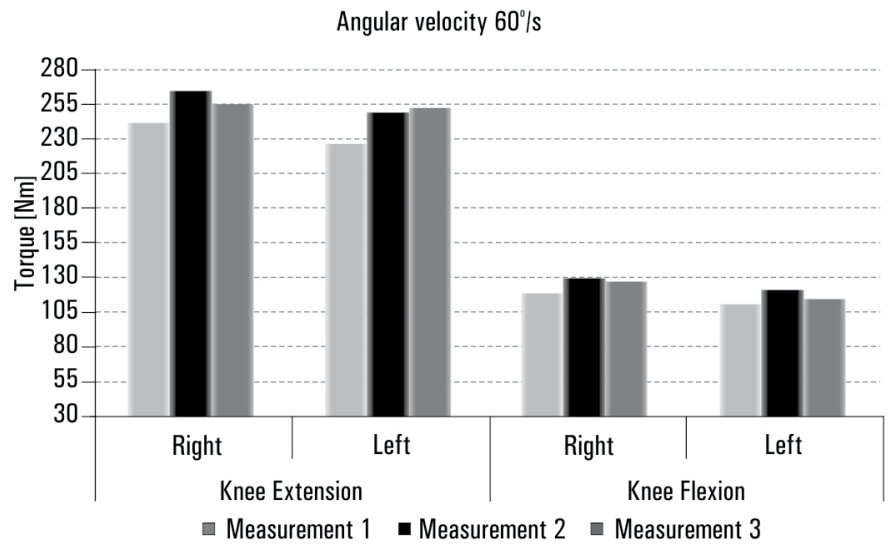

Figure 2. Mean peak torque of the knee flexors and extensors of the right and left limbs in different periods of the macrocycle measured at the velocity of $60 \%$

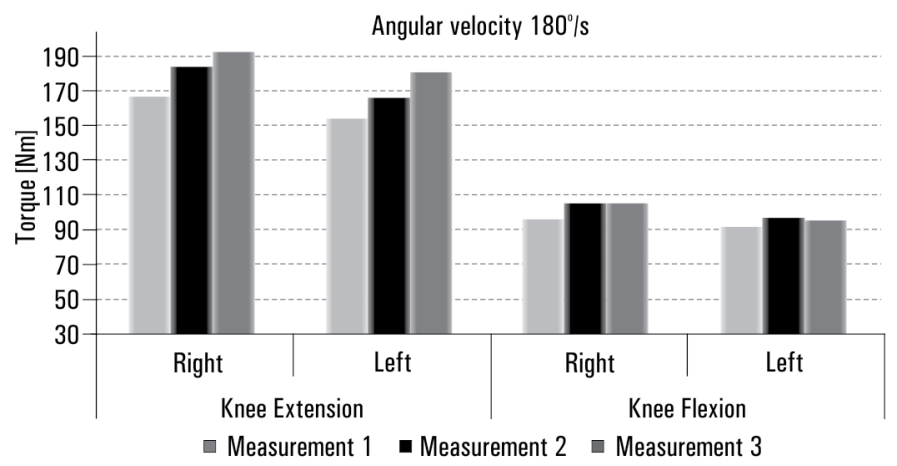

Figure 3. Mean peak torque of the knee flexors and extensors of the right and left limbs in different periods of the macrocycle measured at the velocity of $180^{\circ} / \mathrm{s}$

When the peak torque values obtained for the flexors and extensors of both limbs were compared, the muscles of the right limb were found to be stronger at the velocities of both $60 \%$ and $180 \%$ s. The difference for the velocity of $60 \% \mathrm{~s}$ ranged from $0.7 \%$ to $6.0 \%$ for the extensors and $6.5 \%$ to $9.7 \%$ for the flexors. At the velocity of $180 \%$, this difference ranged from $5.1 \%$ to $9.3 \%$ for the extensors and $4.9 \%$ to $6.6 \%$ for the flexors.

Table 2. Peak flexor to extensor (H:Q) torque ratio values obtained for the right and left limbs at the velocities of $60 \%$ and $180^{\circ} \mathrm{s}$

\begin{tabular}{|c|c|c|c|}
\hline MEASUREMENT & LIMB & $\mathbf{6 0} \% \mathbf{s}$ & $\mathbf{1 8 0} / \mathbf{s}$ \\
\hline \multirow{2}{*}{ Measurement 1 } & Right & $49.2 \%$ & $57.4 \%$ \\
\cline { 2 - 4 } & Left & $48.9 \%$ & $60.1 \%$ \\
\hline \multirow{2}{*}{ Measurement 2 } & Right & $49.1 \%$ & $57.2 \%$ \\
\cline { 2 - 4 } & Left & $48.6 \%$ & $59.8 \%$ \\
\hline \multirow{2}{*}{ Measurement 3 } & Right & $50.1 \%$ & $55.2 \%$ \\
\cline { 2 - 4 } & Left & $45.5 \%$ & $54.3 \%$ \\
\hline
\end{tabular}

Based on the data obtained in the measurements, it was possible to calculate the peak flexor to extensor torque ratio
(H:Q ratio), which served as an indicator of muscle strength. At the velocity of $60 \%$, its mean value was $49.7 \%$ for the right limb almost in all of the measurements and $47.7 \%$ for the left limb. At the velocity of $180 \%$ s, this ratio amounted to $56.6 \%$ for the right limb and $58.1 \%$ for the left one (tab. 2).

\section{Discussion}

An increase in maximum strength, speed, or both as a result of the training improved the players' muscle power [25, 26, 27]. In a study concerning velocity in strength training [28], it was found that exercise with heavy loads done at a slow pace helps increase maximum strength and power in movement performed at a low velocity, while dynamic exercise with lighter loads causes an increase in strength and power for faster movement. In volleyball, more than $70 \%$ of the movement requires speed-strength [29], and for this reason, the players' strength training in the preparatory period focused on strength only, while in the competitive period of the macrocycle, this training was aimed at increasing or maintaining the players' dynamics.

The research described in this article made it possible to measure the torque of the flexors and extensors of the knee joint in isokinetic conditions at the angular velocities of $60 \%$ and $180 \%$ s. An analysis of peak torque values obtained for muscles acting on the knee joint in various periods of the annual training macrocycle showed that after the preparatory period, there was an increase in the strength of the muscles of both the right and left limbs at both velocities, compared to the measurement conducted after the transition period. The increase in the players' strength was satisfactory, and it amounted to approximately $8 \%$ at the velocity of $60 \%$ and over $9 \%$ at that of $180 \%$ s. In a study involving top wrestlers, the sum of peak muscle torque values increased significantly by $4.8 \%$ after the preparatory period, and it fell to the initial level after the competitive period [30]. As far as the results of research involving volleyball players are concerned, it was found that after six months of training, the strength of the main muscle groups had improved by $4.8 \%$ and that of the upper limbs by $13.9 \%$, while the torque values obtained for the lower limbs and trunk had increased by $3.4 \%$ and $1.3 \%$, respectively, though this increase was not statistically significant [31].

After the preliminary round of the season, the results of the measurement changed depending on the velocity of the test. At the velocity of $60 \%$, a decrease in strength compared to the second measurement was observed, and at the velocity of $180 \%$ s, the strength of the muscles acting on the knee joint was found to have increased or remained the same. The increase in strength at the velocity of $180^{\circ}$ s was most likely due to the fact that the players had been performing high volume training, that is training involving lighter loads and faster repetitions.

A comparison of the mean peak torque values obtained for the knee flexors and extensors of the right and left limbs showed that in all cases, for both the velocity of $60 \%$ and that of $180 \%$ s, this difference was less than $10 \%$. This proves that there was no asymmetry between the two limbs, and these results can be seen as satisfactory $[6,14]$. However, a lack of asymmetry is not the norm, since in studies involving female gymnasts, the asymmetry between the right and left limbs was as high as $17 \%$ in some cases [32].

When one compares the flexor to extensor ratio (H:Q ratio) with the available norm $(61 \%$ for the velocity of $60 \%$ and $72 \%$ for the velocity of $180^{\circ} / \mathrm{s}$ ) [6, 33, 34], it is visible that the ratio in the study was considerably lower than the norm for both velocities. The results obtained show that there was a deficit of strength in the knee flexors compared to the extensors. This study thus confirms the observations of other authors [21, 22] who found that the extensors tend to dominate over the flexors 
of the knee joint in competitive volleyball players and saw this phenomenon as typical of this sports discipline.

\section{Conclusions}

The methodology and results of the current study made it possible to perform an objective assessment of the strength of the volleyball players who participated in the study.

In most cases, the results of the measurements which were conducted proved that the training methods used in the macrocycle were appropriate for the players, since there was an increase in torque values obtained for the muscles acting on the knee joint after the preparatory period, while the long and exhausting preliminary round of the season caused a decrease in the strength of the lower limbs at a low velocity.

The results of such measurements carried out in different periods of the volleyball season can help assess the players' strength capacity at a given moment, verify and modify the training methods which are being used, and adopt an individual approach to each player.

\section{Acknowledgements}

The research was financed from the research project implemented by Józef Piłsudski University of Physical Education in Warsaw, the Faculty of Physical Education and Sport in Biała Podlaska - MN.IV/1 - sponsored by the Polish Ministry of Science and Higher Education. The research was also partially financed from grant number 0045/RS3/2015/53 for the "Development of Sports through Universities" awarded by the Ministry of Science and Higher Education.

\section{Literature}

1. Superlak E. (1995). Volleyball. Technical and tactical preparation for the game. Wrocław: Infovolley. [in Polish]

2. Buśko K. (2006). An analysis of the impact of training programmes of different intensity structures on the maximum strength and power of lower limb muscles. Studia i Monografie 109. Warsaw: AWF Warszawa. [in Polish]

3. Czaplicki A. (2009). Modelling in natural coordinates in biomechanics. Biała Podlaska: AWF Warszawa, WWFiS Biała Podlaska. [in Polish]

4. Król H. (2007). Speed-strength performance of ski jumpers. In Cz. Urbanik (ed.), Biomechanics of movement: selected issues (pp. 115-121). Warsaw: AWF Warszawa. [in Polish]

5. Wilkosz P. (2009). Isokinetic assessment of the knee flexors and extensors in competitive volleyball players. Doctoral thesis. Uniwersytet Medyczny, Poznań. [in Polish]

6. Jarocka M., Czaplicki A. (2013). The influence of therapeutic training on changes in selected biomechanical variables after an anterior cruciate ligament reconstruction. Polish Journal of Sport and Tourism 20(1), 13-18.

7. Jaszczuk J., Wit A., Trzaskoma Z., Iskra L., Gajewski J. (1988). Biomechanical criteria of muscle force evaluation in the aspect of top-level athletes selection. Biology of Sport 5(1), 51-64.

8. Trzaskoma Z. (2003). Maximum muscle strength and power in competitive sportsmen and sportswomen. Studia i Monografie 94. Warsaw: AWF Warszawa. [in Polish]

9. Bittencourt N.F.N., Amaral G.M., Saldanha dos Anjos M.T., D’Alessandro R., Silva A.A., Fonseca S.T. (2005). Isokinetic muscle evaluation of the knee joint in athletes of the Under-19 and Under-21 Male Brazilian National Volleyball Team. Revista Brasileira de Medicina do Esporte (11)6, 302-
306.

10. Sheppard J.M., Chapman W.D., Gough C., McGuigan M., Newton R.U. (2009). Twelve-month training-induced changes in elite international volleyball players. Journal of Strength and Conditioning Research 23(7), 2096-2101.

11. Zabka F.F, Valente H.G., Pacheco A.M. (2011). Isokinetic evaluation of knee extensor and flexor muscles in professional soccer players. Revista Brasileira de Medicina do Esporte 17(3), 189-192.

12. Czaplicki A., Dziewiecki K., Sacewicz T. (2012). Identification of internal loads at the selected joint and validation of a biomechanical model during performance of the handspring front somersault. Acta Mechanica et Automatica 6(2), 28-32.

13. Dziewiecki K., Blajer W., Mazur Z., Czaplicki A. (2013). Contact modeling and inverse dynamics identification of the handspring front somersault in pike position. Proceedings of the Institution of Mechanical Engineers, Part K: Journal of Multi-body Dynamics 227(4), 330-343.

14. Ciemniewska-Gorzela K. (2010). Knee joint function after anterior cruciate ligament reconstruction. Doctoral thesis. Uniwersytet Medyczny, Poznań. [in Polish]

15. Hadzic V., Sattler T., Markovic G., Veselko M., Dervisevic E. (2010). The isokinetic strength profile of quadriceps and hamstrings in elite volleyball players. Isokinetics and Exercise Science 18, 31-37. DOI:10.3233/IES-2010-0365

16. West T., Ng L., Campbell A. (2014). The effect of ankle bracing on knee kinetics and kinematics during volleyballspecific tasks. Scandinavian Journal of Medicine Science in Sports 24, 958-963. DOI:10.1111/sms.12130

17. Ribeiro F., Santos F., Goncalves P., Oliveira J. (2014). Effects of volleyball match-induced fatigue on knee joint position sense. European Journal of Sport Science 8(6), 397-402. DOI:10.1080/02614360802373060

18. Borras X., Balius X., Drobnic F., Galilea P. (2011). Vertical jump assessment on volleyball: a follow-up of three seasons of a high-level volleyball team. Journal of Strength and Conditioning Research 25(6), 1686-1694.

19. Sheppard J.M., Nolan E., Newton R.U. (2012). Changes in strength and power qualities over two years in volleyball players transitioning from junior to senior national team. Journal of Strength and Conditioning Research 26(1), 152157.

20. Rodrigez-Ruiz D., Rodrigez-Matoso D., Quiroga M.E., Sarmiento S., Garcia-Manso J.M., Da Silva-Grigoletto M. (2012). Study of mechanical characteristics of the knee extensor and flexor musculature of volleyball players. European Journal of Sport Science 12(5), 399-407. DOI:10.1080/ 17461391.2011.568633

21. Markou S., Vagenas G. (2006). Multivariate isokinetic asymmetry of the knee and shoulder in elite volleyball players. European Journal of Sport Science 6(1), 71-80. DOI:10.1080/17461390500533147

22. Michnik R., Jurkojć J., Czapla K. (2012). Biomechanical assessment of the strength capacity of female volleyball players. Modelowanie Inżynierskie 44, 302-306. [in Polish]

23. Friedrich H., Vetter K. (2003). The value of strength-diagnostic for the structure of jump training in volleyball. European Journal of Sport Science 3, 1-10.

24. Sheppard J.M., Newton R.U. (2012). Long-term training adaptations in elite male volleyball players. Journal of Strength and Conditioning Research 26(8), 2180-2184.

25. Häkkinen K., Komi P.V., Alén M., Kauhanen H. (1987). EMG, muscle fiber and force production characteristics during a 1 year training period in elite weight lifters. European Journal of Applied Physiology 56, 419-427.

26. Häkkinen K. (2000). Neuromuscular adaptation to strength training in men and women and strength athlete. In C.P. 
Lee (ed.), 2nd International Conference on "Weightlifting and Strength Training” (pp. 5-9). Ipoh, Malaysia: Pro Muscle, Department of Education.

27. Jones K., Bishop P., Hunter G., Fleisig G. (2001). The effects of varying resistance-training loads on intermediate- and high-velocity-specific adaptations. Journal of Strength $\mathcal{\sigma}$ Conditioning Research 15(3), 349-356.

28. Kanehisa H., Miyashita M. (1983). Specifity of velocity in strength training. European Journal of Applied Physiology 52(1), 104-106.

29. Grządziel G., Ljach W. (2000). Volleyball. Warsaw: COS. [in Polish]

30. Janiak J., Gajewski J. (1999). Changes in maximum muscle strength in wrestlers in the annual training cycle. Acta of Bioengineering and Biomechanics 1 (suppl. 1), 203-206. [in Polish]

31. Trzaskoma Z., Buśko K., Gajewski J. (2004). Assessment of the level of fitness of sportspersons based on selected biomechanical indicators. In R. Będziński (ed.), Biomechanics and Rehabilitation Engineering (pp. 663-679). Warsaw: Akademicka Oficyna Wydawnicza Exit. [in Polish]

32. Jurkojć J., Michnik R., Skubacz H., Ziółkowska E. (2012). Measuring the muscle torque of gymnasts in isokinetic conditions. Modelowanie Inżynierskie 45, 156-160. [in Polish]

33. Coombs R., Garbutt G. (2002). Developments in the use of the hamstring/quadriceps ratio for the assessment of muscle balance. Journal of Sports Science and Medicine 1(3), 56-62.

34. Sompong Y., Sirirat H., Thyon C. (2002). Hamstring to quadriceps strength ratio in Mahidol Univeristy soccer players. Journal of Health Science 11(5), 681-692.

Submitted: June 17, 2015

Accepted: August 31, 2015 